\title{
Seismic tomography, surface uplift, and the breakup of Gondwanaland: Integrating mantle convection backwards in time
}

\author{
Clinton P. Conrad \\ Seismological Laboratory, California Institute of Technology, Pasadena, California, USA
}

Now at Department of Geological Sciences, University of Michigan, 2534 C.C. Little Bldg., 425 E. University Ave., Ann Arbor, Michigan 48109,USA. (cpconrad@umich.edu)

\section{Michael Gurnis}

California Institute of Technology, Seismological Laboratory, 1200 E. California Blvd., MC 252-21, Pasadena, California 91125, USA (gurnis@gps.caltech.edu)

[1] Mantle density heterogeneities, imaged using seismic tomography, contain information about timedependent mantle flow and mantle structures that existed in the past. We model the history of mantle flow using a tomographic image of the mantle beneath southern Africa as an initial condition while reversing the direction of flow and analytically incorporating cooling plates as a boundary condition. If the resulting (backwards integrated) model for structures is used as a starting point for a forwards convection model, today's mantle can be adequately reconstructed if we do not integrate backwards more than than about 5075 Ma. Flow can also be reliably reversed through the Mesozoic, but only if instability of the lower boundary layer can be suppressed. Our model predicts that the large seismically-slow and presumably hot structure beneath southern Africa produced 500-700 m of dynamic topography throughout the Cenozoic. Since $\sim 30 \mathrm{Ma}$, uplift has moved from eastern to southern Africa, where uplift rates are $\sim 10 \mathrm{~m} / \mathrm{Myr}$, consistent with observations. During the Mesozoic, the modeled topographic high is situated near Gondwanaland rifting, raising the possibility that this buoyant structure may have been involved with this breakup.

Components: 8329 words, 5 figures.

Keywords: Time-dependent convection; mantle structure; dynamic topography; continental uplift; Gondwanaland breakup; African superswell.

Index Terms: 8121 Tectonophysics: Dynamics, convection currents and mantle plumes; 8109 Tectonophysics: Continental tectonics - extensional (0905); 8180 Tectonophysics: Evolution of the Earth: Tomography; 9305 Information Related to Geographic Region: Africa.

Received 31 December 2001; Revised 8 November 2002; Accepted 25 January 2003; Published 29 March 2003.

Conrad, C. P., and M. Gurnis, Seismic tomography, surface uplift, and the breakup of Gondwanaland: Integrating mantle convection backwards in time, Geochem. Geophys. Geosyst., 4(3), 1031, doi:10.1029/2001GC000299, 2003. 


\section{Introduction}

[2] Tomographic models of the mantle's heterogeneous seismic velocity structure have become increasingly detailed over the past decade, and have been used to make important inferences about patterns of mantle flow. For example, the observation that high-velocity anomalies extend from subduction zones into the lower mantle implies that flow in the upper mantle is not distinct from flow in the lower mantle [e.g., Grand et al., 1997; van der Hilst et al., 1997]. Indeed, if we assume that seismic velocity anomalies correspond to density variations that drive mantle flow, we can use these density variations to produce models of the present-day convective flow within the mantle. Such models have been used to constrain the mantle's viscosity structure using the geoid [e.g., Hager, 1984] or dynamic topography [e.g., Lithgow-Bertelloni and Silver, 1998] and its rate of change [e.g., Gurnis et al., 2000].

[3] Because seismic tomography is only available for the present-day, mantle flow models that use tomography to define mantle structure can only be constrained by present-day geological and geophysical observables. There is, however, significant information about the history of mantle flow contained in the motions of plates [Lithgow-Bertelloni and Richards, 1998], geologic observations of surface uplift and subsidence [Gurnis et al., 1998, 2000], the relative motions of hot-spot tracks [e.g., Steinberger and O'Connell, 1998; Steinberger, 2000], temporal variations in Earth's rotation axis [Steinberger and O'Connell, 1997, 2002], the obliquity and precession of Earth's orbit [Forte and Mitrovica, 1997], and the morphology of slabs, whose development is time-dependent [Zhong and Gurnis, 1995]. These time-dependent constraints can be applied to time-dependent models of mantle flow, but such models need an initial condition, which requires an estimate for the density field at some time in the past. One approach to making such estimates has been to impose midMesozoic plate motions until the mantle reaches a quasi steady-state [Bunge et al., 1998]. This initial condition, however, probably does not accurately represent the Mesozoic mantle because plate motions and subduction locations vary with time. Furthermore, the forward advection of plate motions only produces high-density anomalies associated with plate convergence [Lithgow-Bertelloni and Richards, 1998] and can not reproduce the past structure of low-density anomalies.

[4] The morphology of the mantle's present-day heterogeneous density structure is the cumulative result of past time-dependent flow and presumably contains information about the time history of this flow. Thus, it should be possible to reconstruct mantle density structures for times in the past by combining seismic tomography with an understanding of how convective flow responds to and redistributes density heterogeneities. Thus, applying a numerical convection model to the presentday mantle and running it backwards in time should provide a useful estimate of past mantle structure. This method has been demonstrated previously [Bunge and Richards, 1992; Bunge et al., 2003], and has been used to predict observables that are sensitive to the gross redistribution of mantle density heterogeneities throughout the mantle [Forte and Mitrovica, 1997; Steinberger and O'Connell, 1997, 1998, 2002; Steinberger, 2002]. In this work, we investigate the usefulness of reversed flow calculations in the study of more localized problems such as the time history of mantle upwelling beneath southern Africa. Southern Africa is thought to have been uplifted by the upward motion of the African superplume [Lithgow-Bertelloni and Silver, 1998]. Thus, we should be able to constrain time-dependent models of the rise of this tilted structure [Ni et al., 2002] using geologic observations of the time history of African surface uplift.

\section{Reversing Convection in Time}

[5] To estimate the mantle's density field for some time in the past, we use a numerical convection model to reverse convection in time from the mantle's present state. Convection models typically solve the coupled energy and momentum equations as a function of time. For the mantle, the Boussinesq approximation is made, in which the assumption of incompressible flow is consistent with the 
elimination of adiabatic gradients [Backus, 1975; Conrad and Hager, 1999; Hewitt et al., 1975]. Ignoring inertial terms, which are unimportant for mantle flow, the momentum equation is given by:

$$
\frac{\partial \sigma_{i j}}{\partial x_{j}}-\delta \rho g \delta_{i z}=0
$$

where $g$ is the gravitational acceleration (positive downwards) and $\delta \rho=\rho-\rho_{0}$ is density relative to a reference density $\rho_{0}$. Stress is given by $\sigma_{i j}=-p \delta_{i j}+$ $\eta\left(\partial u_{i} / \partial x_{j}\right)$, where $p$ is the pressure, $\eta$ is the dynamic viscosity, and $u_{i}$ is the velocity component. For thermal convection, density anomalies are generated by the thermal expansivity of rock. In this case, $\delta \rho=\rho_{0} \alpha\left(T-T_{0}\right)$, where $T$ and $T_{0}$ are temperature and reference temperature, and $\alpha$ is the coefficient of thermal expansion. This relationship couples the momentum equation to the energy equation, given by:

$$
\frac{\partial T}{\partial t}+u_{i} \frac{\partial T}{\partial x_{i}}=\kappa \frac{\partial^{2} T}{\partial x_{i}^{2}}+H
$$

where $t$ is time, $H$ is the rate of internal heat generation, and $\kappa$ is the coefficient of thermal diffusivity. The left hand side of this equation represents the advection of temperature anomalies by mantle flow. Thus, if we ignore the terms on the right hand side, reversing the direction of mantle flow is equivalent to reversing the direction of time. Because mantle flow is driven by the gravitational body force term in (1), in practice flow reversal can be achieved simply by changing the sign of this term.

[6] A complete time reversal of the coupled energy and momentum equations must also include a time reversal of the right hand side of (2). This is straightforward for the internal heating term $H$, but unfortunately the diffusive term becomes unstable when reversed in time. Temperature gradients become amplified rapidly in such a calculation, making the direct reversal of this term impossible. Adjoint methods have been developed [e.g., Bunge et al., 2003] that invert for a past mantle temperature field that is consistent with both diffusion and advection of heat over time. Such models successfully reproduce present-day tomography when run forwards to the present-day, but require more than 100 times the computational requirements of a single backwards advection calculation [Bunge et al., 2003]. We show below, however, that patterns of thermal diffusion in the mantle are such that useful models of past mantle structure can be obtained by simply reversing the direction Stokes flow.

[7] For the mantle interior, thermal diffusion is exceedingly slow. The time scale, $t_{c}$, for heat to diffuse over a distance $d$ is given by [e.g., Turcotte and Schubert, 1982]:

$$
t_{c} \sim \frac{d^{2}}{4 \kappa}
$$

Most structures in the mantle interior, particularly low-velocity anomalies, have length scales of $\sim 500 \mathrm{~km}$ or more. For $\kappa=10^{-6} \mathrm{~m}^{2} \mathrm{~s}^{-1}$, this length scale implies a diffusion time scale of 2 billion years, a significant fraction of the age of the Earth. Thus, for the mantle interior away from the boundary layers, thermal diffusion is an unimportant processes, and can be ignored in a reverse convection calculation.

[8] In the upper and lower thermal boundary layers, however, thermal diffusion is the dominant mode of heat transport and special attention must be given to these layers in a reverse convection calculation. For the upper boundary layer, thermal diffusion produces plates with an error function temperature profile and a thickness that is related to the age of the plate according to (3). Thus, the thermal structure of the upper thermal boundary layer is a known function of plate age. As a result, we can reconstruct the thermal structure of the upper boundary layer as a function of time in the past by combining known present-day plate ages with plate reconstructions that give plate location as a function of time. If the thermal structure of the upper boundary layer is specified, it does not participate directly in the dynamical aspects of flow below that layer. In this case boundary layer instabilities do not affect the lithosphere or the underlying mantle, cold material does not accumulate near ridges when plate motions are reversed, and any uncertainty in the boundary layer's thermal structure will not directly affect mantle flow. All of 
these problems adversely affect the reversibility of convection in models that do not include special treatment of the upper boundary layer [Bunge et al., 2003]. Thus, by reconstructing the upper boundary layer through time, we can focus on interior mantle structures.

[9] We can not, however, constrain the past or present structure of the lower boundary layer, and therefore we must impose its structure arbitrarily. As a result, all of the problems that we avoid by reconstructing the upper thermal boundary layer remain important for the lower boundary layer. For the earth, the lower boundary layer is thought to produce thin, rising plume jets that exert minimal influence on mantle-scale flow [e.g., Steinberger and O'Connell, 1998; Steinberger, 2000]. As we shall see, the degree to which flow in the mantle interior can be reversed in time depends on how this flow is affected by the unknown structure of the lower boundary layer.

[10] Even in the absence of thermal diffusion Stokes flow is not reversible indefinitely. For example, the backwards advection of a low-density structure will eventually yield a stratified and inverted density field, with low-density material spread uniformly across the base of the fluid. At this point, all information about the eventual morphology and placement of the original low-density structure will be lost and a forward calculation from this point will not reproduce the original structure. Thus, the requirement that structures not become too stratified or laterally distorted places a limit to how far back in time densitydriven flow can be reversed [Kaus and Podladchikov, 2001].

[11] Finally, our ability to reverse mantle flow will be limited by our knowledge of past plate motions, which are well-constrained only through the Cenozoic and Mesozoic [e.g., Engebretson et al., 1985, 1992]. Ideally, the Earth's tectonic plates should be driven by the gravitational pull of dense slabs of subducted lithosphere, as is expected for the Earth [e.g., Conrad and Lithgow-Bertelloni, 2002; Hager, 1984; Lithgow-Bertelloni and Richards, 1998]. However, although slabs can be imaged tomographically [e.g., Grand et al., 1997; van der Hilst et al., 1997], including the coupling between slabs and plates in a dynamic model remains technically challenging [e.g., Conrad and Hager, 2001; Zhong et al., 1998]. Yet in order to make useful predictions that can be tested geologically, a time-dependent convection model should include the correct history of surface plate motions. Since this is not currently achievable in a dynamical way, it is necessary to prescribe plate motions using velocity boundary conditions. The combination of buoyancy-induced flow in the mantle and velocity boundary conditions at the surface has been shown to yield identical results to dynamical models with the same viscosity structure [Han and Gurnis, 1999], and has been used previously in time-dependent models of mantle convection [e.g., Bunge et al., 1998; Gurnis et al., 1998; Steinberger and O'Connell, 1997, 1998, 2002; Steinberger, 2000].

\section{Time-Dependent Convection Models for Gondwanaland}

[12] We use the breakup of Gondwanaland as a test case for demonstrating the procedure of reversing convection and then using the resulting timedependent model to make testable predictions. We chose this example for several reasons. First, the tectonic history of Gondwanaland is simple and it is well-constrained (it primarily involves spreading, for which the geologic record is well-preserved [e.g., Norton and Sclater, 1979]). Second, the role of convergent plate boundaries, which are difficult to treat even in forward models [e.g., Conrad and Hager, 2001; Zhong and Gurnis, 1995] and which would be even more difficult for backward convection, is minimal in the tectonics of Gondwanaland breakup. Finally, tomography beneath southern Africa, near the original center of Gondwanaland, reveals a low-velocity anomaly with a diameter of order $2000 \mathrm{~km}$ [Ni et al., 2002; Ritsema et al., 1999; van Heijst and Woodhouse, 1999]. This anomaly has been interpreted to be a region of hot mantle, and the "African Superswell," a region of high topography stretching across southern Africa and the south Atlantic [Nyblade and Robertson, 1994], has been attributed to dynamic topography associated with the 
rise of the mantle anomaly [Gurnis et al., 2000; Lithgow-Bertelloni and Silver, 1998].

[13] We used a variation of the spherical finite element code CitComs [Zhong et al., 2000] to solve the coupled momentum and energy equations as a function of time on a three-dimensional sector of a sphere. This sector is bounded above by the Earth's surface, below by the core-mantle boundary, and on its sides by the set of points that extend radially from lines of latitude and longitude at the surface toward the center of the Earth. Boundary conditions on the sides and at the base require that flow be parallel to these boundaries, and we impose velocities at nodes on the surface, including those on its edges, that are consistent with plate motions. Temperature boundary conditions are insulating on the sides and prescribed at the surface and base. We perform calculations on a grid of 120 elements spanning 90 degrees of latitude $\left(-60^{\circ}\right.$ to $\left.30^{\circ}\right), 160$ elements spanning 120 degrees of longitude $\left(-50^{\circ}\right.$ to $\left.70^{\circ}\right)$, and 60 elements spanning the $2867 \mathrm{~km}$ depth of the mantle. This calculation was performed on 144 nodes of a 308 node "Beowulf" cluster of PCs constructed at the Seismological Laboratory at Caltech.

[14] To generate temperatures and velocity boundary conditions for the upper boundary layer, we reconstructed plate ages and velocities as a function of time backward into the Mesozoic. This was done by rotating current plate locations, with corresponding plate ages given by Müller et al. [1997], backward in time using the rotation poles of Müller et al. [1993]. The resulting plate velocities were used as surface velocity boundary conditions, and the plate ages were used to determine the temperature structure of the upper $200 \mathrm{~km}$ of the finite element grid. In doing so, we assumed an error-function temperature profile with characteristic depth given by (3) and that $50 \%$ of the superadiabatic temperature variation across the mantle $(3000 \mathrm{~K})$ occurs in the upper boundary layer [e.g., Turcotte and Schubert, 1982, pp. 190-195]. Continents were assigned an age of $300 \mathrm{Ma}$, which does not reproduce the temperature structure of continents [Vitorello and Pollack, 1980], but does produce a deep continental root.
[15] Because we do not have useful tomographic information about thickness variations in the lower boundary layer, we assigned an error function temperature profile with an arbitrarily chosen characteristic depth of $100 \mathrm{~km}$ and $50 \%$ of the total super-adiabatic temperature variation to the bottom $100 \mathrm{~km}$ of the finite element grid. Given that the surface area of the core-mantle boundary is only $30 \%$ that of the Earth's surface, this boundary layer is consistent with that of a mantle that is $30 \%$ heated from below. This figure for the fraction of bottom-heating is larger than the value of $10 \%$ estimated from hotspot heat flow [Sleep, 1990], but recent studies suggest that the heat flux from the core should be higher than this [Labrosse, 2002; Romanowicz and Gung, 2002]. As a result, our parameterization of the lower boundary layer provides an approximate upper bound on its importance to mantle flow. Because we later show that the amount of time over which we can reliably reverse convection largely depends on the degree to which the lower boundary layer affects mantle flow, our use of an upper bound on its importance places a lower bound on how far backward in time we can reverse mantle flow.

[16] Because we apply our calculations to only a portion of the mantle and because we impose the thermal structure of the boundary layers, we do not expect to reproduce the thermal balance of the current mantle. Thus, for simplicity and because the distribution of heat-producing elements is the subject of some debate [e.g., Becker et al., 1999], we do not include internal heating in our calculations, so $H=0$ in (2). This has the effect of slightly increasing the effect of the lower boundary layer on mantle flow, and is consistent with our attempt to place an upper bound on the importance of this layer. In addition, the effect of internal heating would be small; a mantle with a heat production rate of $H=6.18 \times 10^{-12} \mathrm{~W} \mathrm{~kg}^{-1}$ and a heat capacity of $920 \mathrm{~J} \mathrm{~kg}^{-1} \mathrm{~K}^{-1}$ would experience a temperature increase of only $21 \mathrm{~K}$ over the last 100 Ma [e.g., Turcotte and Schubert, 1982, pp. 139141, pp. 332-333]. If applied uniformly within the mantle, this degree of heating would have little effect on the movement of thermal anomalies in the mantle, which is the subject of this study. 
[17] Temperatures between the upper and lower boundary layers are assigned a value that depends on seismic tomography. The relationship between the shear velocity anomaly, $\delta v_{s}$, and a density anomaly, $\delta \rho$, is:

$$
\delta \rho=\frac{\partial \rho}{\partial v_{s}} \delta v_{s}
$$

The proportionality constant that relates density to velocity anomaly is often given as $\left(\partial \rho / \partial v_{s}\right) /\left(\rho_{0} / \beta\right)$, where $\rho_{0}$ is the reference density and $\beta$ is the the reference shear velocity. We use a value of 0.4 here, which is consistent with values used in other studies [e.g., Lithgow-Bertelloni and Silver, 1998; Steinberger, 2000] and is close to estimates from laboratory studies [Karato, 1993] and geoid modeling [Forte et al., 1993]. We combine this value with $\rho_{0}=3300 \mathrm{~kg} \mathrm{~m}^{-3}$ and $\beta=6.5 \mathrm{~km} / \mathrm{s}$, typical values for the lower mantle, to obtain $\partial \rho / \partial v_{s}=200 \mathrm{~kg} \mathrm{~m}^{-3} / \mathrm{km} \mathrm{s}^{-1}$. This value is close to previous estimates [e.g., Hager et al., 1985], and is well within the range of $50-400 \mathrm{~kg} \mathrm{~m}^{-3} / \mathrm{km} \mathrm{s}^{-1}$ considered by Gurnis et al. [2000] to fit the present-day African topography and its rate of change. Although both $\rho_{0}$ and $\beta$ vary with depth in the mantle, we use constant values here because we are only interested in the non-adiabatic components of these quantities.

[18] Estimates of density anomaly are useful for Stokes flow calculations, but for a fully timedependent convection calculation, we need to convert anomalous density to anomalous temperature. This can be achieved using:

$$
\delta T=\frac{1}{\alpha \rho_{0}} \delta \rho
$$

where $\alpha=3 \times 10^{5} \mathrm{~K}^{-1}$ is the thermal expansivity, which is assumed constant here despite evidence for a decrease of $\alpha$ with depth [Chopelas and Boehler, 1992] because the uncertainty in other parameters is greater. Combining (4) and (5), we obtain a relationship between $\delta T$ and $\delta v_{s}$ of 2000 $\mathrm{K} / \mathrm{km} \mathrm{s}^{-1}$. We apply this conversion to shear velocities provided by the degree -20 shear wave velocity model (S20RTS), which was inverted from surface wave phase velocities, body wave travel times, and free-oscillation splitting measure- ments [Ritsema et al., 1999; van Heijst and Woodhouse, 1999].

[19] Viscosity depends on temperature according to the relationship for dislocation creep given by [e.g., Kohlstedt et al., 1995]:

$$
\eta(T)=\eta_{m} \exp \left(\frac{E_{a}}{R T}-\frac{E_{a}}{R T_{m}}\right)
$$

where $R=8.31 \mathrm{~J} \mathrm{~mol}^{-1} \mathrm{~K}^{-1}$ is the universal gas constant, $E_{a}=100 \mathrm{~kJ} / \mathrm{mol}$ is an activation energy often used in numerical studies [e.g., Conrad and Hager, 1999; Gurnis et al., 2000] and consistent with a Newtonian representation of non-Newtonian mantle flow [Christensen, 1984]. The temperature offset $T_{m}$ and reference viscosity $\eta_{m}$ are chosen according to the requirements of the intended viscosity structure. For the three-dimensional examples below, we choose $\eta_{m}$ so that at an upper mantle temperature of $T_{m}=1500^{\circ} \mathrm{C}$, the upper mantle has a specified viscosity of $\eta_{u m}=10^{21} \mathrm{~Pa} \mathrm{~s}$. The lower mantle viscosity is chosen to have a value 30 times larger, which is consistent with observations of gravity and postglacial rebound [e.g., Mitrovica and Forte, 1997], as well as the geoid and plate motions [e.g., Lithgow-Bertelloni and Richards, 1998]. Because viscosity is temperature-dependent, the viscosity that determines rates of deformation will be that of hotter mantle with lower viscosity [Parmentier et al., 1976]. Thus, although volume-weighted average viscosities of about $\eta=10^{21} \mathrm{~Pa} \mathrm{~s}$ and $\eta=3 \times 10^{22} \mathrm{~Pa} \mathrm{~s}$ apply for the upper and lower mantles, effective viscosities should be lower than this, and approximately consistent with the Haskell constraint of $\eta=$ $10^{21} \mathrm{~Pa} \mathrm{~s}$ for the top $1400 \mathrm{~km}$ of the mantle [Haskell, 1935; Mitrovica, 1996].

\subsection{Three-Dimensional Examples}

[20] As a first example of how mantle convection can be reversed in time, we used the present-day seismic tomography model of Ritsema et al. [1999] and the present-day plate configuration as the starting point for convective flow (Figure 1a). We then ran convection in reverse while imposing reverse plate motions and specifying the thermal structure of the upper boundary layer. Because some diffusion of heat is necessary to ensure numerical 
a) $\mathrm{Age}=\mathbf{0} \mathrm{Ma}$
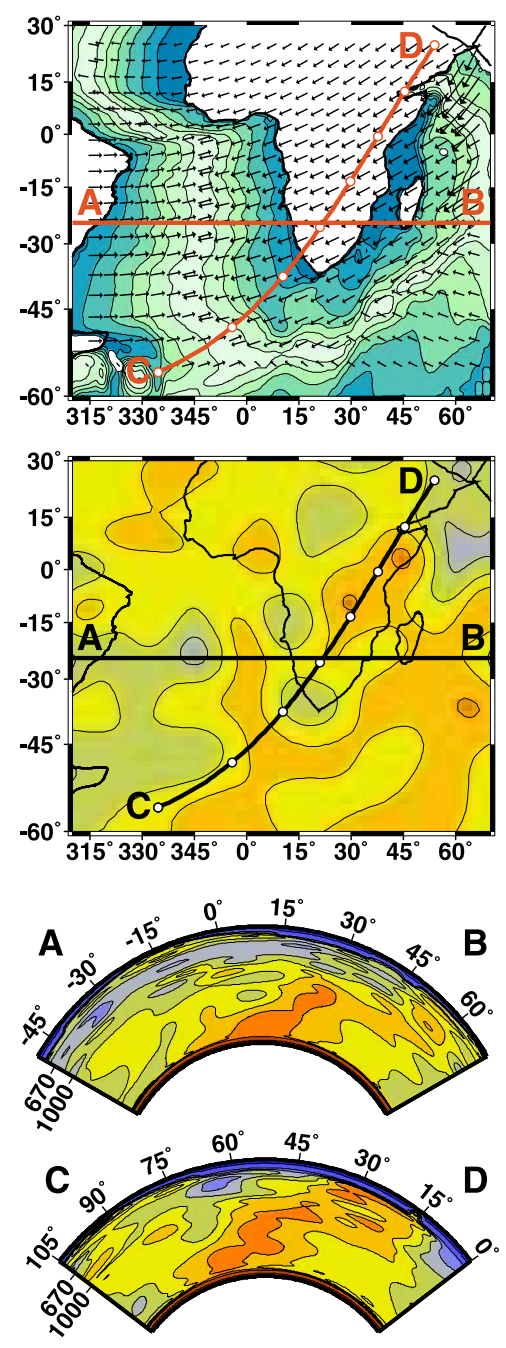

b) Start = $0 \mathrm{Ma}$, End = $75 \mathrm{Ma}$
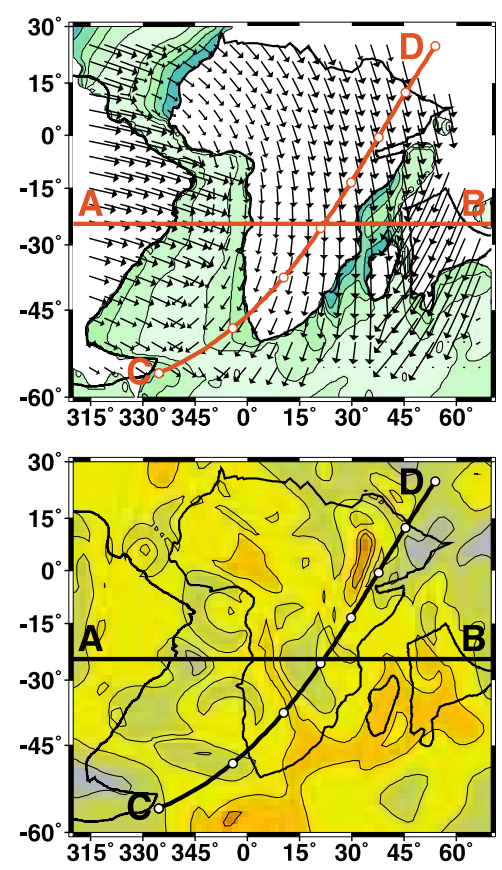

c) Start = $75 \mathrm{Ma}$, End $=2 \mathrm{Ma}$
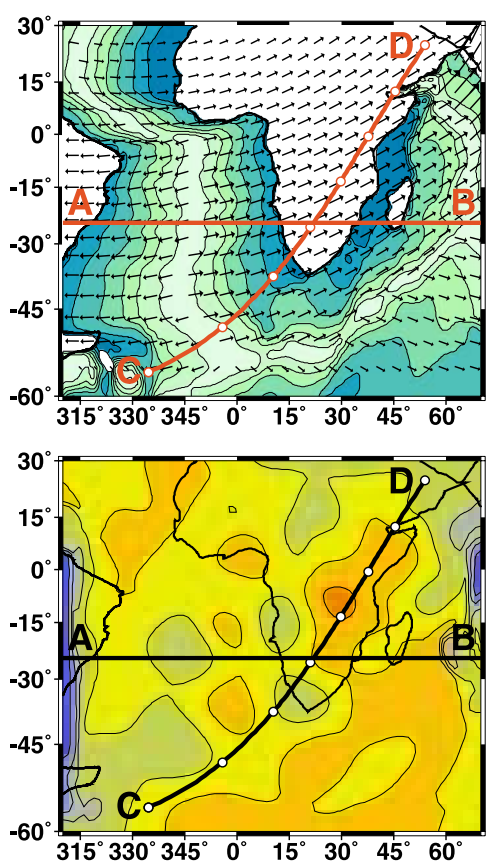
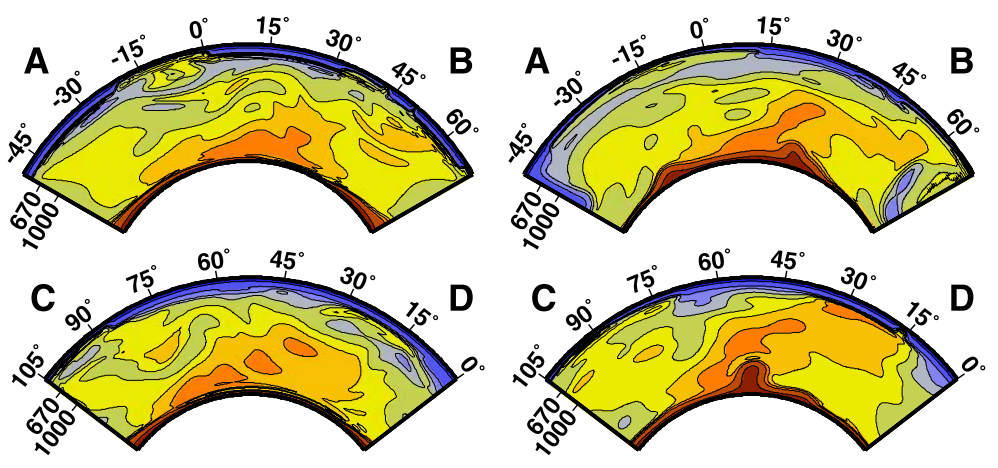

Temperature (C)

\section{$0 \quad 10001300 \quad 14001450 \quad 150015501600 \quad 1700 \quad 2000 \quad 3000$}

Figure 1. Three dimensional convection calculations running from (a) the present day, backwards in time to (b) 75 Ma, and then forwards in time back to (c) near the present-day at $2 \mathrm{Ma}$. Shown in the top row are the plate velocities that are used to implement surface velocity boundary conditions and the plate ages (with a 20 Ma contour interval) that are used to reconstruct the temperature structure of the upper thermal boundary layer. Note that in Figures 1a and 1b the velocities are reversed because the calculation is run backwards in time. Temperatures are shown in colors in the next three rows for a planform of the temperature field at a depth of $1000 \mathrm{~km}$ and for cross sections following the small circle (transect A-B) and the great circle (transect C-D). A comparison of Figures 1a and 1c shows that mantle structures are well recovered after convection is run backwards to $75 \mathrm{Ma}$ in Figure $1 \mathrm{~b}$ and then forwards to $2 \mathrm{Ma}$ in Figure 1c.

stability [King et al., 2001], thermal diffusion was integrated forwards in time during the reversal stage, but we decreased thermal diffusivity by a factor of 1000. The calculation was initially run backwards in time for 75 million years (Figure 1b). At this stage, Gondwanaland has been partially reassembled and the large hot structure beneath southern Africa has partially collapsed, descending deeper into the lower mantle (vertical cross sections, Figure 1b) and falling primarily below 1000 $\mathrm{km}$ depth (planform cross section, Figure 1b). This downwelling flow has flattened the lower boundary 
layer, pushing it outwards toward the edges of the calculation. At the same time, some of the colder structures on the periphery have risen.

[21] To test whether the structures recovered at 75 Ma (Figure 1b) still retain information about the structures that develop for the present day, we ran the calculation forwards in time from $75 \mathrm{Ma}$ to near the present day (Figure 1c). This was done by restoring the direction of flow and the value of thermal diffusivity and imposing surface velocities and upper-boundary layer temperatures that are consistent with plate velocities and ages. Comparing the retained timestep closest to $0 \mathrm{Ma}$ in the forwards integration to present-day tomography (Figures 1a and 1c) shows that many features of the present-day mantle are recovered, although some are not. For example, the large hot structure beneath southern Africa regains its approximate height, rising above $1000 \mathrm{~km}$ in the planform cross section (Figure 1c). The original shape of this upwelling is nearly recovered, including its tilt toward the north-east. The cold structure above and to the west of the central upwelling is largely recovered. Large cold downwellings, however, are predicted near the boundaries in the final calculation (Figure 1c) that were not present initially. These are artifacts related to the interaction of cold material below continents with the velocity conditions on the boundaries of the box. Special attention to these boundaries, including the prescription of temperatures in these regions, could be used to diminish these structures [e.g., Tan et al., 2002]. Perhaps the most notable discrepancy is the significantly thicker lower boundary layer in the recovered calculation. This feature is caused by the extra $75 \mathrm{Ma}$ over which the lower boundary layer is allowed to grow.

[22] We explored the feasibility of going further backward in time by integrating convection backwards from the present day (Figure 2a) to the middle of the Mesozoic, stopping at $126 \mathrm{Ma}$ when Gondwanaland was beginning to break apart (Figure $2 b$ ). The recovery attempt, performed by running convection forwards to almost the present day (Figure 2c) bears little resemblance to the presentday mantle (Figure 2a). The recovered structure is dominated by several localized hot upwelling plumes and sheets rising from the lower boundary layer while the present-day tomography is dominated by one large upwelling beneath southern Africa. Clearly in $126 \mathrm{Myr}$ the lower boundary layer has become thick enough, and sufficiently unstable, to produce hot upwelling plumes and attached jets that are not observed in the presentday tomography. Plume jets may be less than 500 $\mathrm{km}$ in diameter and may not be obvious when viewed through the filter of seismic tomography [e.g., Bijwaard and Spakman, 1999]. Ideally, a predicted temperature field (Figure 2c) should be re-imaged using the tomographic inversion procedure when being compared to tomographic images (Figure 2a). This may diminish predicted plume features and improve the correlation between the predicted and observed fields. The upwelling plumes in Figure 2c, however, are dominant enough to have changed the basic flow structure of the surrounding mantle, making it unlikely that a re-imaged comparison would lead to a significant improvement.

[23] To quantify the deterioration of our ability to recover mantle structure after running convection progressively farther backwards in time, we measure the correlation coefficient between the entire temperature field of the present-day mantle (Figures 1a and 2a) and the entire temperature field after convection has been run backwards and forwards for a given amount of time (Figures 1c and 2c). Results for the above three dimensional calculations, as well as ones for different times (Figure 3a, thick black line) show that the correlation coefficient decreases as convection is reversed for a greater period of time. In particular, at about $70 \mathrm{Ma}$, the correlation coefficient drops markedly, signifying an increased disruption of mantle flow by plumes from the unstable lower. This time scale is also consistent with studies of time-dependent convection that successfully predict true polar wander through the Cenozoic, but become increasingly discrepant with observations before that time [Steinberger and O'Connell, 1997, 2002].

\subsection{Two-Dimensional Models}

[24] The role of plumes in disrupting our ability to recover mantle structures depends largely on the 
a) $\mathrm{Age}=\mathbf{0} \mathrm{Ma}$
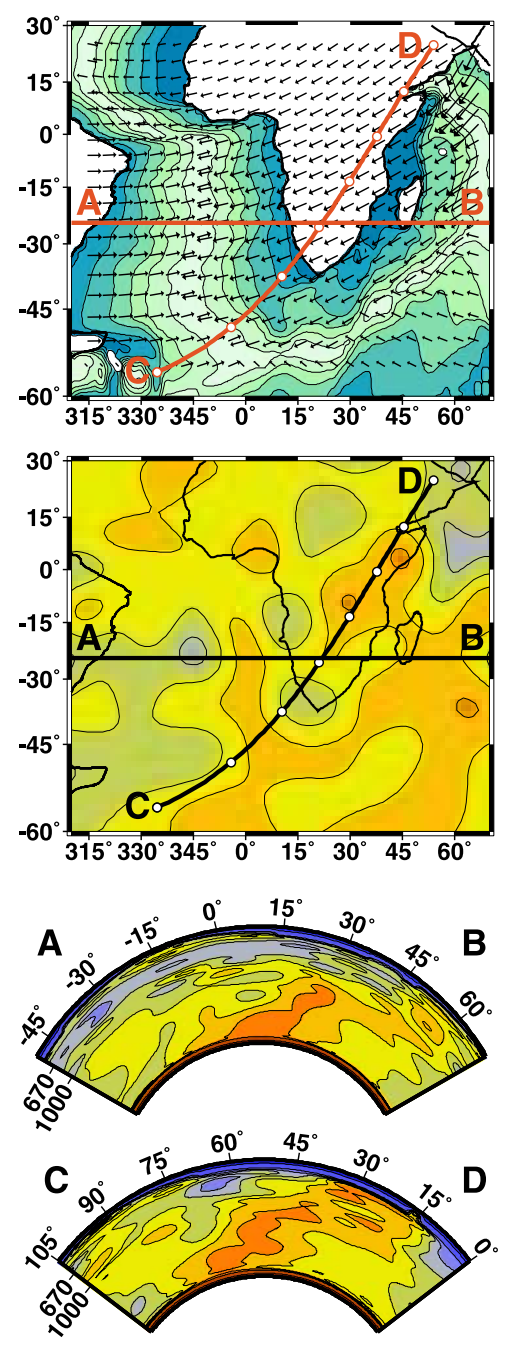

b) Start = $0 \mathrm{Ma}$, End $=126 \mathrm{Ma}$
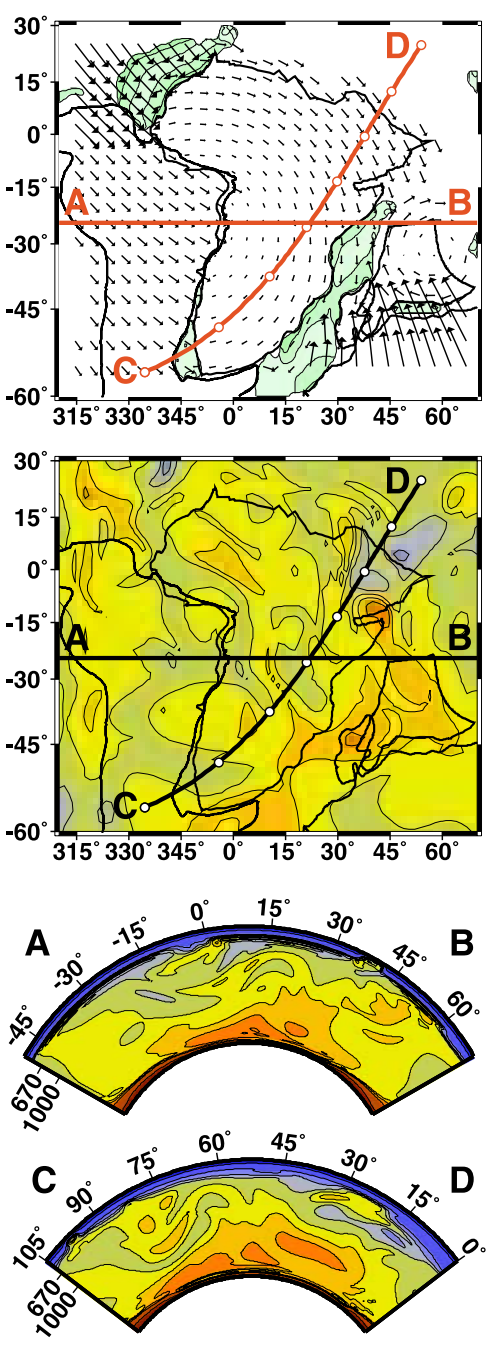

Temperature (C)
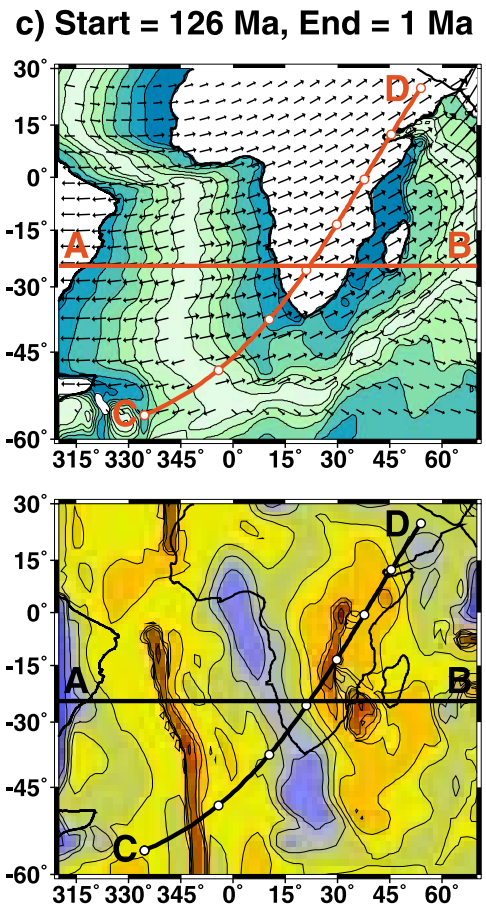

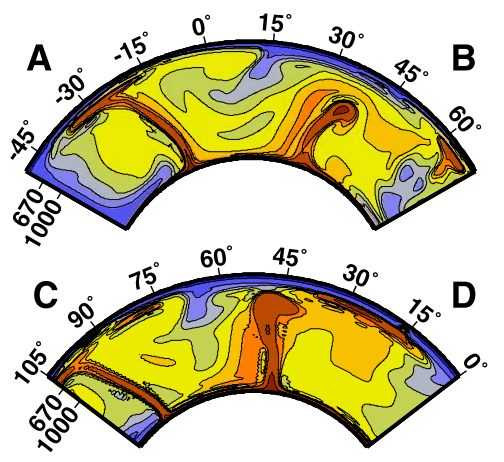

Temperature (C)

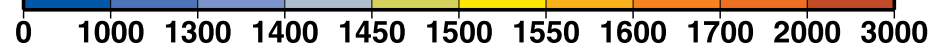

Figure 2. Similar to Figure 1, but for a calculation that runs backward in time from (a) the present-day to (b) 126 $\mathrm{Ma}$ and then forward in time to (c) $1 \mathrm{Ma}$. A comparison of Figures $2 \mathrm{a}$ and $2 \mathrm{c}$ shows that present-day mantle structures are not well recovered by this series of calculations due to the unstable growth of plumes that rise from the lower boundary layer.

degree of instability of the lower thermal boundary layer. Perturbations to this layer grow exponentially with time at rates that depend inversely on its viscosity [e.g., Conrad and Molnar, 1999]. To demonstrate the importance of viscosity, we repeated the experiment described above for different relationships between temperature and viscosity. To save time, we performed this set of experiments in two dimensions along a sector running from $-50^{\circ}$ to $70^{\circ}$ longitude along the $24.75^{\circ}$ south latitude line (the A-B line in Figures 1 and 2). In these calculations, we used only the east-west component of the plate velocities as velocity boundary conditions.

[25] We varied viscosity by setting the pre-exponential factor $\eta_{m}$ in (6) so that at a temperature of $T=1500^{\circ} \mathrm{C}$, the upper mantle has a specified viscosity of $\eta_{u m}=3 \times 10^{20}, 10^{21}, 3 \times 10^{21}$, or $10^{22} \mathrm{~Pa} \mathrm{~s}$, and the lower mantle viscosity is 30 
a)
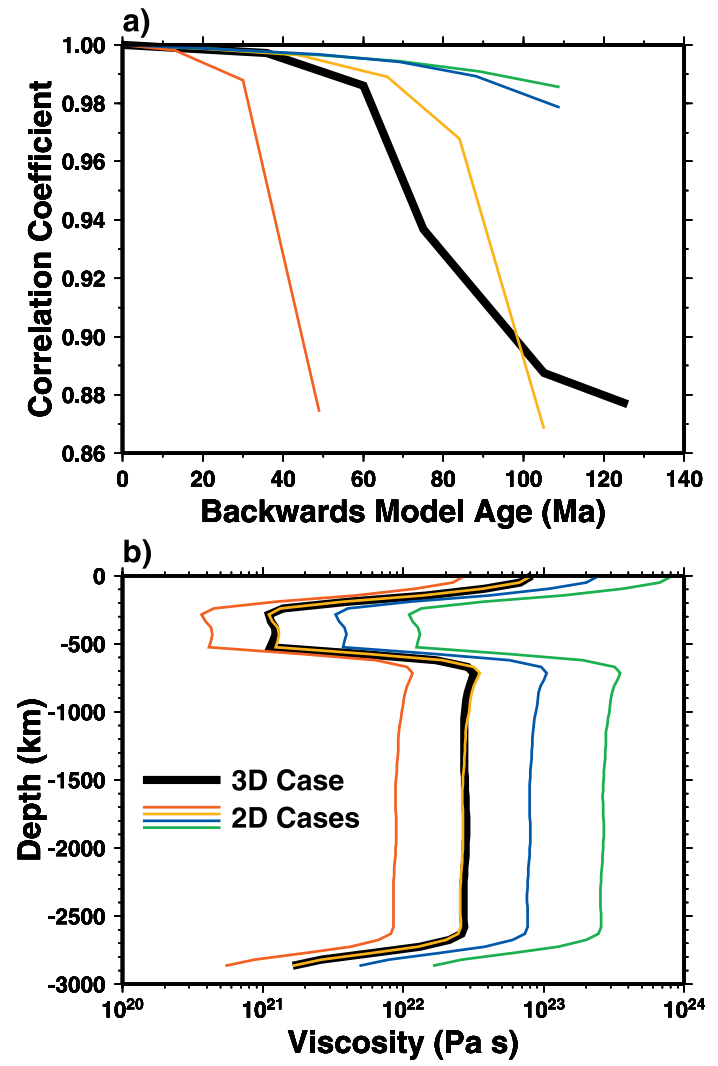

Figure 3. (a) The correlation coefficient that compares the temperature field for the present-day with the temperature field obtained by running convection backwards for a given time (x-axis) and then forwards to the present-day. The correlation coefficient uses temperature information from all depths and thus gives a global measure of how well the original temperature structure has been recovered. A perfect correlation has a value of unity. Results are shown for the three-dimensional convection calculation (thick black line) and for several two-dimensional calculations (colored thin lines) that differ in their assigned viscosities. The volumeweighted average value of these viscosities is shown as a function of depth in Figure $3 b$.

times larger (Figure 3b). After running convection backwards and forwards for different amounts of time, we again found that correlation decreases with model age but that the age at which it does so depends on viscosity (Figure 3a). Because boundary layer instability scales inversely with viscosity, the low viscosity case (red line) decorrelates at $40 \mathrm{Ma}$, while the higher viscosity cases (blue and green lines) do not significantly decorrelate for the entire $126 \mathrm{Ma}$ history. Because the rate of deformation of all mantle structures scales inversely with viscosity, increasing the mantle viscosity has the effect of slowing down the calculation, and the decorrelation of all mantle structures occurs proportionally later in time.

\section{Time-Dependent Dynamic Topography}

[26] If their integration backwards in time is limited, these three-dimensional convection calculations provide a model for how mantle structure evolved as Gondwanaland broke apart. This model assumes a viscosity structure for the mantle, and is designed to yield present-day mantle density heterogeneities that are consistent with seismic tomography. The resulting time history of mantle flow should also yield several predictions that can be tested against geologic observations at the surface. For example, upwelling mantle flow generates stresses at the Earth's surface that manifest themselves as uplift (i.e., dynamic topography [Gurnis, 1993; Hager et al., 1985]). This type of uplift has been used to explain the elevated plateaus of southern Africa and the surrounding oceans [Gurnis et al., 2000; Lithgow-Bertelloni and Silver, 1998]. The models presented here make predictions of how the African continent was uplifted over time.

[27] Dynamic topography can be calculated using the total vertical stress on the surface, $\sigma_{z z}$. For a deformable boundary such as the surface of the Earth, this stress translates directly into topography according to $h=\sigma_{z z} /(\Delta \rho g)$, where $\Delta \rho=3300 \mathrm{~kg} \mathrm{~m}^{-3}$ is the density difference between the mantle and air [e.g., Hager et al., 1985]. Because the velocity boundary conditions used in these models exert a traction on the surface that may influence dynamic topography, we recalculate the dynamic topography for each given time from a Stokes flow calculation that uses the temperature field for that time and a free-slip boundary condition at the surface. Because the lithosphere is cold and therefore strong, this boundary condition mimics the Earth's in that upwelling mantle rises beneath effectively rigid, but potentially mobile, surface plates.

[28] We have calculated dynamic topography as a function of time (Figure 4) using the three-dimen- 
a) Age $=0 \mathrm{Ma}$

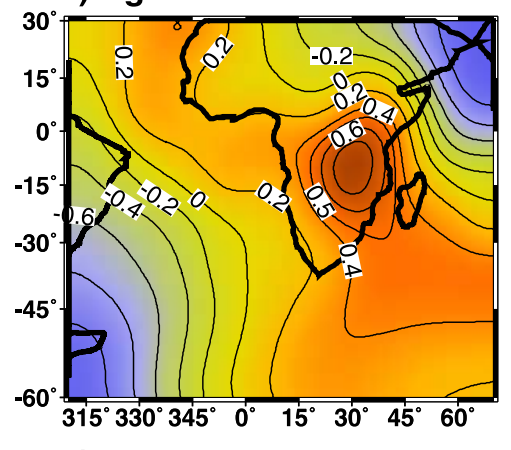

d) Age = $75 \mathrm{Ma}$

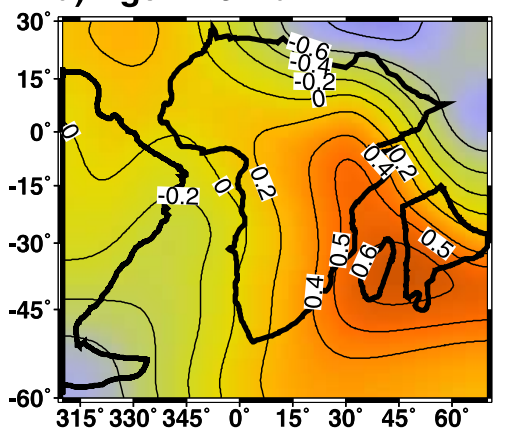

b) Age = $36 \mathrm{Ma}$

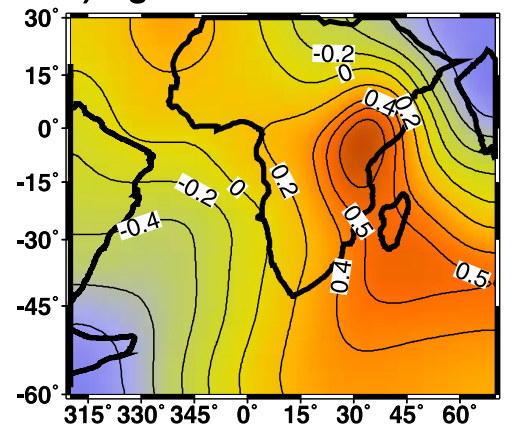

e) Age $=105$

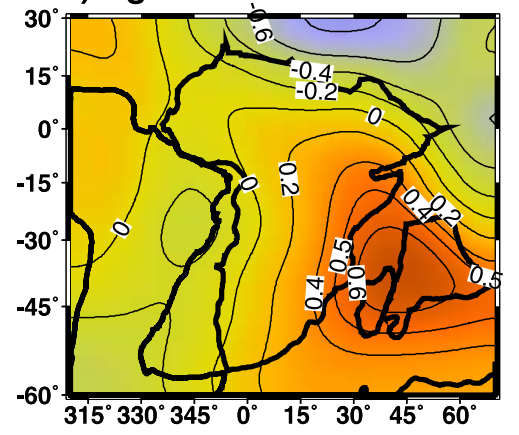

c) Age $=60 \mathrm{Ma}$

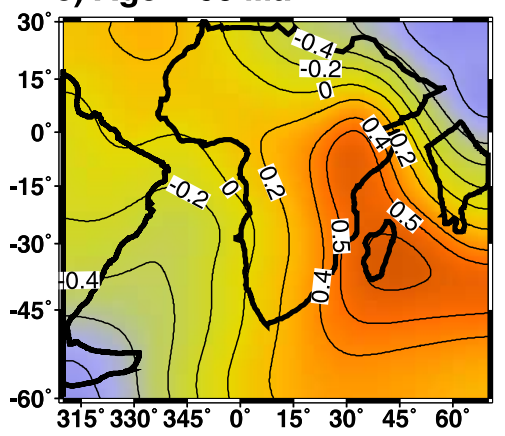

f) Age = $126 \mathrm{Ma}$

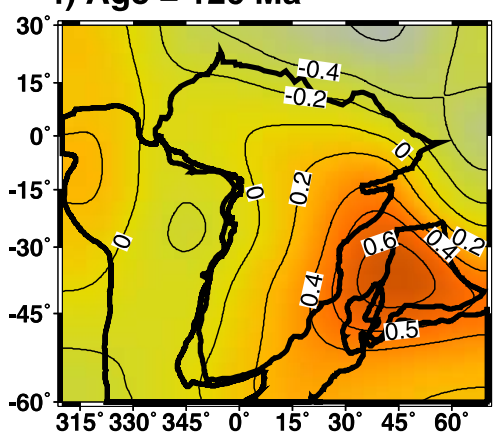

Figure 4. Dynamic topography $(\mathrm{km})$ as a function of time for a model in which convection is run backwards in time to $126 \mathrm{Ma}$, the time of the opening of Gondwanaland. These predictions of topography can be compared to geologic observations of surface uplift through time in Africa.

sional backwards convection calculations. As noted, the recoverability of structure is diminished for ages greater than $75 \mathrm{Ma}$ because of lower boundary layer instability (Figure 2). These plumes are formed independently of the flow associated with the large upwelling beneath Africa, which dominates the dynamic topography. If the boundary layer were less unstable, the upwelling beneath Africa would grow undisrupted, and the recoverability of mantle structure would remain high for model runs farther backwards in time. Thus, we present dynamic topography estimates (Figure 4) that are calculated from the reversed convection run, for which boundary layer instability is not a problem. As a result, it is likely that our results are valid farther backward in time than the $75 \mathrm{Ma}$ that is evident from Figure 3.

[29] Our predictions of dynamic topography (Figure 4) are dominated by a topographic high associated with the rise of the large upwelling currently beneath southern Africa. This high topography generally has a maximum amplitude of about $600-700 \mathrm{~m}$, but the location of this maximum changes, both in absolute space, and relative to the continents. At the present-day (Figure 4a), the maximum elevates southern Africa by about 700 $\mathrm{m}$, but as the calculation progresses further backward in time, it predicts that this maximum moved from east Africa at $36 \mathrm{Ma}$ (Figure 4b) and from the Indian Ocean, near Madagascar, at $60 \mathrm{Ma}$ (Figures 4c and 4d). Between 75 and $126 \mathrm{Ma}$, the maximum was centered in the growing rift between the African, Indian and Antarctic plates as they split away from Gondwanaland (Figures 4e and 4f).

[30] This model for time-dependent dynamic topography can be compared to geologic observations that constrain uplift of the Earth's surface over time. For present-day Africa, significantly uplifted plateaus exist in a band stretching from eastern to southern Africa, with elevations of $1200 \mathrm{~m}$ or more. The amplitude and location of this elevated region is in approximate agreement with the $700 \mathrm{~m}$ topographic high shown in Figure 4a, although the high topography of Africa stretches farther to the north and south. Although eastern Africa today is significantly higher than $700 \mathrm{~m}$, much of this 
a) 36 to $0 \mathrm{Ma}$

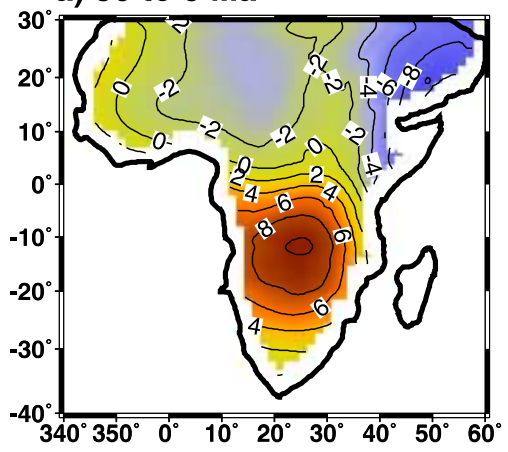

b) 60 to $36 \mathrm{Ma}$

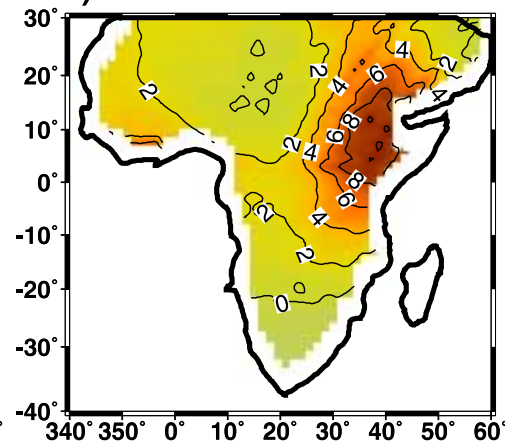

c) 75 to $60 \mathrm{Ma}$

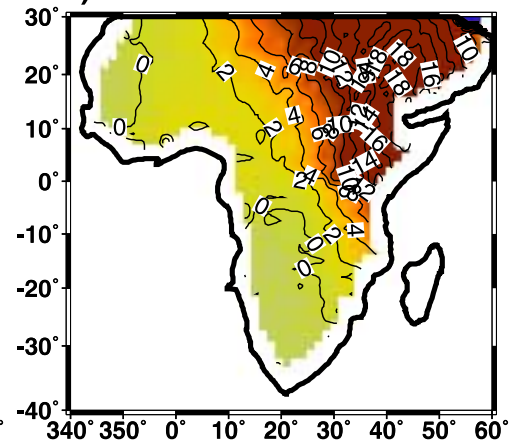

Figure 5. Predictions of uplift rate on the African continent, shown in meters per million years, for various time periods. Uplift rate is calculated by differencing snapshots of predicted dynamic topography (Figure 4) while taking into account the motion of the African plate between these snapshots.

elevation is probably not dynamic topography but rather related to volcanic activity and rifting that began in eastern Africa at $\sim 30 \mathrm{Ma}$ [Burke, 1996].

[31] The calculations performed here also allow us to estimate rates of uplift as a function of time. Geologic observations of uplift rate are typically made by estimating sedimentation rates both on land and in the ocean, and by determining the tilting of erosional surfaces and fission track ages of exhumed rocks. Because such measurements are made in the reference frame of a moving plate, it is useful to express uplift rates on the African continent after taking into account the motion of Africa (Figure 5). These calculations show that the region of fastest uplift moves from eastern Africa at $75 \mathrm{Ma}$ (Figure 5c) toward southern Africa in the present day (Figure 5a). The model's prediction of uplift rates are approximately consistent with geologic estimates. Gurnis et al. [2000] estimate uplift in southern Africa to be between 5 and 30 $\mathrm{m} / \mathrm{Myr}$. The lower bound of this range is based on Partridge and Maud's [1987] estimate of 150$300 \mathrm{~m}$ of uplift occurring during the mid-Miocene and observed as tilting of the ancient African surface. The higher estimates are based on Burke's [1996] suggestion that up to $800 \mathrm{~m}$ of uplift occurred over the past $30 \mathrm{Myr}$. Our calculations predict a maximum of $10 \mathrm{~m} / \mathrm{Myr}$ of uplift in southern Africa during the last $36 \mathrm{Myr}$, which is well within Partridge and Maud's [1987] observations, but is significantly slower than Burke's [1996].
[32] The time-dependent nature of these calculations allows us to compare predicted and observed uplift rates for time periods throughout the Cenozoic, although geologic estimates for times before the Miocene are difficult to obtain. We predict a migration of uplift that progresses from eastern to southern Africa and an acceleration of uplift during the Cenozoic (Figures 5a, 5b, and 5c). This sequence is approximately consistent with a midMiocene uplift of southern Africa [Partridge and Maud, 1987], and an initiation of uplift and rifting in east Africa between 20 and $30 \mathrm{Ma}$ [Burke, 1996; Partridge, 1997]. The overall lower dynamic topography of Arabia, North Africa, and West Africa is consistent with marine inundation of these areas from $\sim 95$ to $\sim 45$ Ma [Smith et al., 1994]. The recent accelerated sinking of Arabia (Figure 5a) can be attributed to downwelling flow along the boundary of the calculation, and thus is not relevant to a geologic event.

[33] The time-varying uplift and rates of uplift predicted by our calculation depend on the model parameters that control the mantle viscosity and density structure. In particular, the amplitudes of dynamic topography and its time derivative are directly proportional to the magnitude of the density heterogeneity, produced here using seismic tomography and a value of $\partial \rho / \partial v_{s}=200 \mathrm{~km}$ $\mathrm{m}^{-3} / \mathrm{km} \mathrm{s}^{-1}$ [e.g., Gurnis et al., 2000; Hager et al., 1985]. This quantity is not particularly well constrained and may be depth-dependent [Karato, 1993; Forte et al., 1993]. As a result, the ampli- 
tudes of dynamic topography and its time derivative (Figures 4 and 5) are uncertain by perhaps a factor of two [Gurnis et al., 2000].

[34] Uncertainty in the mantle's viscosity structure adds a further layer of complexity to the calculations. Assuming the same depth-dependence, manthe viscosity does not affect the amplitude of dynamic topography, but it does control it's rate of change. If mantle viscosity were higher than the values used here by a simple scalar factor, then the rate at which the hot mantle upwelling rises would be slowed by this factor. This would cause timedependent uplift patterns (Figure 4) to occur over a longer period of time, decreasing uplift rates (Figure 5) by this scalar factor. Furthermore, the plate motions imposed as boundary conditions are tied to geologic observations and not to mantle viscosity. This causes the location of plates relative to regions of maximum uplift to change. For example, the movement of the topographic maximum from eastern Africa toward southern Africa between $36 \mathrm{Ma}$ and the present (Figures $4 \mathrm{a}$ and $4 \mathrm{~b}$ ) is primarily due to north-eastward motion of Africa during this time. A more rapid rise of upwellings would not only increase uplift rates, but would condense them within a more recent time interval, causing more uplift in southern Africa, rather than eastern. Changes in the temperature- or depth-dependence of viscosity would change the model results in an even less straightforward way.

\section{Conclusions}

[35] The calculations presented here show that it is possible to reverse mantle convection in time using a numerical convection model. In doing so, the past mantle can be reconstructed from present-day seismic tomography, at least for a limited amount of time into the past. The factors that control the amount of time over which convection can be reversed are determined partly by the time over which information about the present mantle is lost as convection is run backwards toward a stable, stratified configuration [Kaus and Podladchikov, 2001]. This time period depends on the total amount of mantle deformation, and thus is related to convective velocities determined by mantle viscosity. A second limiting factor involves diffusion of heat, which can not be reversed in time. In the mantle interior, the role of diffusion is limited, and thermal diffusion in the upper boundary layer can be modeled effectively using the known history of plate motions. Diffusion of heat into the lower boundary layer, however, provides a more substantial problem and is indeed the factor that eventually disrupts convection in the calculations performed here (Figure 2c). As discussed above, we use a parameterization of the lower boundary layer that places an upper bound on its possible importance to global-scale mantle flow. Thus, our estimate of $75 \mathrm{Ma}$ over which it is possible to reliably reverse convection in time is a lower bound on this time scale.

[36] If we wish to study mantle processes that are not affected by instability of the lower boundary layer, we could impose a fixed thermal structure for that layer, as we did for the upper boundary layer. In this case, it should be possible to reverse convection through the Mesozoic, after which uncertainties in surface plate motions begin to become important. The suppression of disruptive boundary layer instability is essentially accomplished by adjoint models that use inversion techniques to determine past mantle structure [Bunge et al., 2003]. Because such models reproduce the present-day tomography by design, boundary layer instability does not disrupt flow because it is not an obvious feature of present-day tomographic images. If the thermal structure of the boundary layer can be ignored altogether and replaced instead by insulating boundary conditions on temperature, then calculations similar to those presented here could be performed with lower resolution. In this case, a greater number of models could be run and the effects of different model parameters tested. It should be possible, for example, to use the time history of uplift to test models with different parameterizations of viscosity or different scalings between seismic velocity and temperature.

[37] Reversing convection in time produces a model of past mantle structure. This model is only useful if it makes predictions that can be tested against present-day observables. Here, we compare 
predictions of the time history of dynamic topography to observations of African uplift history. Although the geologic history of uplift is at times difficult to constrain, our predictions are consistent with available geologic observations and show a period of uplift for eastern Africa during the first half of the Cenozoic and for southern Africa since about 30 Ma. This uplift occurs as Africa moves north-eastward over a hot mantle upwelling that is seen today as a large low-velocity structure beneath southern Africa. Rates of uplift are also consistent with geologic estimates.

[38] The calculations presented here make other predictions that could potentially be tested. For example, the uplift maximum is located near the center of rifting between Africa, Madagascar, and India that led to the breakup of Gondwanaland at $126 \mathrm{Ma}$ (Figure 4f). This raises the question of whether large-scale mantle upwelling and the related surface uplift could have caused the observed rifting. The association between the two is supported by the later coincidence of the topographic high with the onset of rifting in eastern Africa (Figure 4b). Geologic evidence for significant uplift in the vicinity of a rifting event such as the one that disassembled Gondwanaland would help constrain the time-dependence of convection and lead to a better understanding of possibly related processes such as continental breakup. Some such evidence exists, such as the observation that rivers in India primarily flow from west to east, which indicates a previous history of uplift in the west that may be associated with the emplacement of the Deccan traps at $65 \mathrm{Ma}$ [Cox, 1989]. More such observations that better determine the timing and the rates of past uplift will prove useful in constraining the time-history of mantle convection and its affect on surface geology.

\section{Acknowledgments}

[39] This work was supported by National Science Foundation grants EAR-9814577 and EAR-9910387, and by an O. K. Earl Fellowship and a National Science Foundation Postdoctoral Research Fellowship for Conrad. We thank D. Komatits and J. Tromp for help in the design and assembly of the Beowulf computer cluster, L. Han for help in altering the "CitComS" code for use in this work, and M. Billen for helpful discussions. This manuscript was improved thanks to reviews by B. Steinberger, J. X. Mitrovica, R. J. O'Connell, and an anonymous referee.

\section{References}

Backus, G. E., Gross thermodynamics of heat engines in deep interior of Earth, Proc. Natl. Acad. Sci. U.S.A., 72, 15551558, 1975.

Becker, T. W., J. B. Kellogg, and R. J. O'Connell, Thermal constraints on the survival of primitive blobs in the lower mantle, Earth Planet. Sci. Lett., 171, 351-365, 1999.

Bijwaard, H., and W. Spakman, Tomographic evidence for a narrow whole mantle plume below Iceland, Earth Planet. Sci. Lett., 166, 121-126, 1999.

Bunge, H.-P., and M. A. Richards, The backward problem of plate tectonics and mantle convection, Eos Trans. AGU, 73, 281, 1992.

Bunge, H.-P., M. A. Richards, C. Lithgow-Bertelloni, J. R. Baumgardner, S. P. Grand, and B. A. Romanowicz, Time scales and heterogeneous structure in geodynamic Earth models, Science, 280, 91-95, 1998.

Bunge, H.-P., C. R. Hagelberg, and B. J. Travis, Mantle circulation models with variational data assimilation: Inferring past mantle flow and structure from plate motions histories and seismic tomography, Geophys. J. Int., 152, 280-301, 2003.

Burke, K., The African plate, S. Afr. J. Geol., 99, 341-409, 1996.

Christensen, U., Convection with pressure- and temperaturedependent non-Newtonian viscosity, Geophys. J. R. Astron. Soc., 77, 343-384, 1984.

Chopelas, A., and R. Boehler, Thermal expansivity in the lower mantle, Geophys. Res. Lett., 19, 1983-1986, 1992.

Conrad, C. P., and B. H. Hager, Effects of plate bending and fault strength at subduction zones on plate dynamics, J. Geophys. Res., 104, 17,551-17,571, 1999.

Conrad, C. P., and B. H. Hager, Mantle convection with strong subduction zones, Geophys. J. Int., 144, 271-288, 2001.

Conrad, C. P., and C. Lithgow-Bertelloni, How mantle slabs drive plate tectonics, Science, 298, 207-209, 2002.

Conrad, C. P., and P. Molnar, Convective instability of a boundary layer with temperature- and strain-rate-dependent viscosity in terms of 'available buoyancy', Geophys. J. Int., 139, 51-68, 1999.

Cox, K. G., The role of mantle plumes in the development of continental drainage patterns, Nature, 342, 873-877, 1989.

Engebretson, D. C., A. Cox, and R. G. Gordon, Relative motions between oceanic and continental plates in the Pacific basin, Spec. Pap. Geol. Soc. Am., 206, 1-59, 1985.

Engebretson, D. C., K. P. Kelley, H. J. Cashman, and M. A. Richards, 180 million years of subduction, GSA Today, 2, 93-100, 1992.

Forte, A. M., and J. X. Mitrovica, A resonance in the Earth's obliquity and precession over the past 20 Myr driven by mantle convection, Nature, 390, 676-680, 1997.

Forte, A. M., A. M. Dziewonski, and R. L. Woodward, Aspherical structure of the mantle, tectonic plate motions, non- 
hydrostatic geoid, and topography of the core-mantle boundary, in Dynamics of the Earth's Deep Interior and Earth Rotation, Geophys. Monogr. Ser., vol. 72, edited by J.-L. Le Mouël, D. E. Smylie, and T. Herring, pp. 135-166, AGU, Washington, D.C., 1993.

Grand, S. P., R. D. van der Hilst, and S. Widiyantoro, Global seismic tomography: A snapshot of convection in the Earth, GSA Today, 7, 1-7, 1997.

Gurnis, M., Phanerozoic marine inundation of continents driven by dynamic topography above subducting slabs, Nature, 364, 589-593, 1993.

Gurnis, M., R. D. Müller, and L. Moresi, Dynamics of Cretaceous vertical motion of Australia and the Australian-Antarctic Discordance, Science, 279, 1499-1504, 1998.

Gurnis, M., J. X. Mitrovica, J. Ritsema, and H.-J. van Heijst, Constraining mantle density structure using geological evidence of surface uplift rates: The case of the African superplume, Geochem. Geophys. Geosyst., 1, Paper Number 1999GC000035, 2000.

Hager, B. H., Subducted slabs and the geoid: Constraints on mantle rheology and flow, J. Geophys. Res., 89, 6003-6015, 1984.

Hager, B. H., R. W. Clayton, M. A. Richards, R. P. Comer, and A. M. Dziewonski, Lower mantle heterogeneity, dynamic topography and the geoid, Nature, 313, 541-545, 1985.

Han, L., and M. Gurnis, How valid are dynamic models of subduction and convection when plate motions are prescribed?, Phys. Earth. Planet. Int., 110, 235-246, 1999.

Haskell, N. A., The motion of a fluid under a surface load, 1, Physics, 6, 265-269, 1935.

Hewitt, J. M., D. P. McKenzie, and N. O. Weiss, Dissipative heating in convective flows, J. Fluid Mech., 68, 721-738, 1975.

Karato, S., Importance of anelasticity in the interpretation of seismic tomography, Geophys. Res. Lett., 20, 1623-1626, 1993.

Kaus, B. J. P., and Y. Podladchikov, Forward and reverse modeling of three-dimensional viscous Rayleigh-Taylor instability, Geophys. Res. Lett., 28, 1095-1098, 2001.

King, S. D., A. Raefsky, and B. H. Hager, ConMan: vectorizing a finite element code for incompressible two-dimensional convection in the Earth's mantle, Geophys. Res. Lett., 28, 1095-1098, 2001.

Kohlstedt, D. L., B. Evans, and S. J. Mackwell, Strength of the lithosphere: Constraints imposed by laboratory experiments, J. Geophys. Res., 100, 17,587-17,602, 1995.

Labrosse, S., Hotspots, mantle plumes and core heat loss, Earth Planet. Sci. Lett., 199, 147-156, 2002.

Lithgow-Bertelloni, C., and M. A. Richards, The dynamics of Cenozoic and Mesozoic plate motions, Rev. Geophys., 36, 27-78, 1998.

Lithgow-Bertelloni, C., and P. G. Silver, Dynamic topography, plate driving forces and the African superswell, Nature, 395, 269-272, 1998.

Mitrovica, J. X., Haskell [1935] revisited, J. Geophys. Res., 101, 555-569, 1996.

Mitrovica, J. X., and A. M. Forte, Radial profile of mantle viscosity: Results from the joint inversion of convection and postglacial rebound observables, J. Geophys. Res., 102, 2751-2769, 1997.

Müller, R. D., J.-Y. Royer, and L. Lawver, Revised plate motions relative to the hotspots from combined Atlantic and Indian Ocean hotspot tracks, Geology, 21, 275-278, 1993.

Müller, R. D., W. R. Roest, J.-Y. Royer, L. M. Gahagan, and J. G. Sclater, Digital isochrons of the world's ocean floor, J. Geophys. Res., 102, 3211-3214, 1997.

Ni, S., E. Tan, M. Gurnis, and D. Helmberger, Sharp sides to the African superplume, Science, 296, 1850-1852, 2002.

Norton, I. O., and J. G. Sclater, A model for the evolution of the Indian Ocean and the breakup of Gondwanaland, J. Geophys. Res., 84, 6803-6830, 1979.

Nyblade, A. A., and S. W. Robinson, The African superswell, Geophys. Res. Lett., 21, 765-768, 1994.

Parmentier, E. M., D. L. Turcotte, and K. E. Torrance, Studies of finite amplitude non-Newtonian thermal convection with application to convection in the Earth's mantle, J. Geophys. Res., 81, 1839-1846, 1976.

Partridge, T. C., Late Neogene uplift in eastern and southern Africa and its paleoclimatic implications, in Tectonic Uplift and Climate Change, edited by W. F. Ruddiman, pp. 63-86, Plenum, New York, 1997.

Partridge, T. C., and R. R. Maud, Geomorphic evolution of southern Africa since the Mesozoic, S. Afr. J. Geol., 90, 179-208, 1987.

Ritsema, J., H. J. van Heijst, and J. H. Woodhouse, Complex shear wave velocity structure related to mantle upwellings beneath Africa and Iceland, Science, 286, 1925-1928, 1999.

Romanowicz, B., and Y. Gung, Superplumes from the coremantle boundary to the lithosphere: implications for heat flux, Science, 296, 513-516, 2002.

Sleep, N. H., Hotspots and mantle plumes: some phenomenology, J. Geophys. Res., 95, 6715-6736, 1990.

Smith, A. G., D. G. Smith, and B. M. Funnell, Atlas of Cenozoic and Mesozoic Coastlines, Cambridge Univ. Press, New York, 1994.

Steinberger, B., Plumes in a convecting mantle: Models and observations for individual hotspots, J. Geophys. Res., 105, 11,127-11,152, 2000.

Steinberger, B., and R. J. O'Connell, Changes in the Earth's rotation axis owing to advection of mantle density heterogeneities, Nature, 387, 169-173, 1997.

Steinberger, B., and R. J. O'Connell, The convective mantle flow signal in rates of true polar wander, Geophys. J. Int., 132, 412-434, 1998.

Steinberger, B., and R. J. O'Connell, Advection of plumes in mantle flow: Implications for hotspot motion, mantle viscosity and plume distribution, in Ice Sheets, Sea Level, and the Dynamic Earth, Geodyn. Ser, vol. 29, edited by J. X. Mitrovica and L. L. A. Vermeersen, pp. 233-256, AGU, Washington, D.C., 2002.

Tan, E., M. Gurnis, and L. Han, Slabs in the lower mantle and their modulation of plume formation, Geochem. Geophys. Geosyst., 3(11), 1067, doi:10.1029/2001GC000238, 2002.

Turcotte, D. L., and G. Schubert, Geodynamics, John Wiley, New York, 1982. 
van der Hilst, R. D., S. Widiyantoro, and E. R. Engdahl, Evidence of deep mantle circulation from global tomography, Nature, 386, 578-584, 1997.

van Heijst, H.-J., and J. H. Woodhouse, Global high-resolution phase velocity distributions of overtone and fundamentalmode surface waves determined by mode branch stripping, Geophys. J. Int., 137, 601-620, 1999.

Vitorello, I., and H. N. Pollack, On the variation of continental heat flow with age and the thermal evolution of continents, J. Geophys. Res., 85, 983-995, 1980.
Zhong, S., and M. Gurnis, Mantle convection with plates and mobile, faulted plate margins, Science, 267, 838-843, 1995.

Zhong, S., M. Gurnis, and L. Moresi, Role of faults, nonlinear rheology, and viscosity structure in generating plates from instantaneous mantle flow models, J. Geophys. Res., 103, 15,255-15,268, 1998.

Zhong, S., M. T. Zuber, L. N. Moresi, and M. Gurnis, The role of temperature-dependent viscosity and surface plates in spherical shell models of mantle convection, J. Geophys. Res., 105, 11,063-11,082, 2000. 